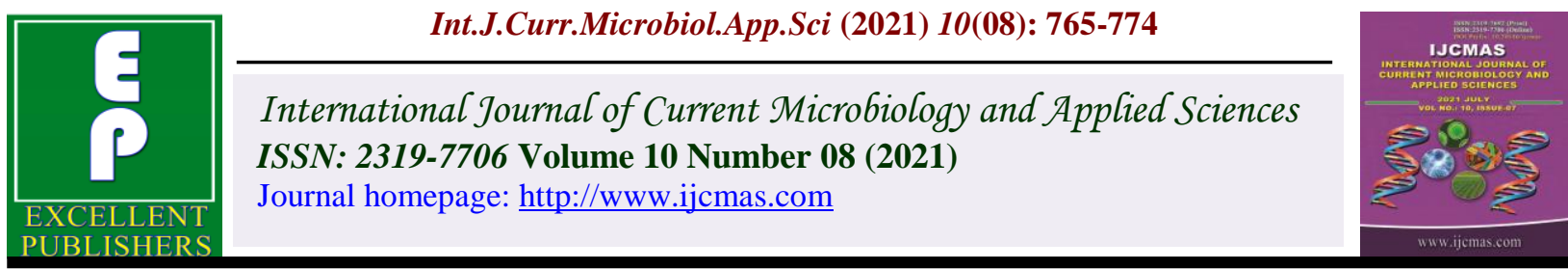

Original Research Article

https://doi.org/10.20546/ijcmas.2021.1008.086

\title{
Microbial Load and Resistance Pattern of Bacteria Organisms in the Gastrointestinal Tract of Household Rat
}

\author{
J.E. Egbagba ${ }^{1^{*}}$, U.B. Owhe-Ureghe ${ }^{2}$, M.A. Alex-Wele ${ }^{3}$, S.D. Lawson ${ }^{4}$ and L.A. Orutugu ${ }^{5}$ \\ ${ }^{1}$ Department of Medical Microbiology, Federal Medical Centre Yenagoa, Nigeria \\ ${ }^{2}$ Department of Microbiology, Faculty of Science, Delta State University, Abraka, Nigeria \\ ${ }^{3}$ Deartment of Medical Microbiology, University of Port Harcourt Teaching Hospital \\ Port Harcout, Nigeria \\ ${ }^{4}$ Department of Medical Microbiology and Parasitology, Rivers State University, Port \\ Harcourt, Nigeria \\ ${ }^{5}$ Department of Medical Microbiology and Parasitology, Niger Delta University, \\ Wilberforce Island, Amassoma, Nigeria \\ *Corresponding author
}

\section{A B S T R A C T}

\section{Keywords}

House hold rats, Antimicrobial resistance organisms, Abraka, Zoonotic diseases

Article Info

\section{Accepted:}

25 July 2021

Available Online:

10 August 2021
Household rats are known agents of human diseases worldwide. They are vehicles of transmission of bacteria, viral, fungal and protozoal disease to man. Rats and human guts with similarities are colonized with normal flora that can harbour multidrug-resistant organisms transmissible to man. This study investigates the microbial load of household rats and their resistance micro-organisms which are transmissible to man. This knowledge is useful for household rat disease burden management in our environment and in healthcare setting. A cross-sectional descriptive and analysis of 200 trapped rat collected from 100 household in Abraka, Nigeria after consent were obtained. The trapped rats were killed, dissected and swab taken from each throat, small and large intestine respectively for analysis of bacteria and fungi load (Using serial, dilution and viable count method). Other biochemical tests for bacteria and fungi analysis were done according to standard Microbiology methods. The results obtained shows more bacteria load in small intestine of household rats compared to throat and large intestines. Bacteriodes fragilis and Escherichia coli were the predominant bacteria obtained, while Candida albicans and other Candida species were the most abundant fungi seen. More than two-third of the bacteria isolates were resistant to commonly used antibiotics such as Ampicillin, Penicillin, Trimetoprinsuphamethoxazole, and Cefriazone. Households rats in our study indicate a high burden of bacteria and fungi load with increased bacteria resistance. Reporting of this zoonotic disease associated with these organisms, proper diagnosis and management are required to mitigate this potential source burden of these disease causing agents. 


\section{Introduction}

The house mouse (Mus musculus) infestation has been a worldwide problem for ages and are known reservoirs of a number of human diseases. ${ }^{1}$

Rodents are known agents of many human bacterial, viral, protozoa and fungal diseases ${ }^{1,2,3}$. They have been linked with the risks and transmission of diseases such as Salmonellosis, Campylobacteriosis, Gastroenteritis, Candidiasis, rat bite fever, leptospirosis, plague, and murine typhus epidemic $^{3,4}$. Additionally the presence of household rats have been associated with multidrug resistant organisms that are likely transmittable to $\operatorname{man}^{4,3,5}$.

General agreement exist about the similarities of rat and human gut normal flora. These consist of facultative bacteria such as Streptococcus, Staphylococcus, Escherichia coli and other Entero bacteriacae, however, the anaerobic bacteria predominate especially in the large gut with bacteriodes fragilis, bifido bacterium and Lactobacilli. ${ }^{67,}$, . Similarly, the predominant fungi which colonize the gut includes Candida albican, other candida species, Malassezia furfur and the filamentous fungus, Cladosporium. ${ }^{9}{ }^{10}$.

Although various researches have looked at rat gut microbial composition in relation to human disease transmission, however few have looked at its antimicrobial resistant organism that are possibly transmissible to man.

There are scanty studies about rat zoonotic diseases in our environment and most zoonotic diseases are under reported. This poses a health risk to the populace and difficulty in disease management. ${ }^{11}$ This article therefore set out to determine the microbial load of household rats and its antibiotic resistance organism that are transferable to man. The outcome of this study could be useful for furtherance of rat zoonotic diseases management in our environment and in healthcare setting.

\section{Materials and Methods}

\section{Study Design and sampling}

This cross-sectional analytical study was carried out in Abraka community in Ethiope East local Government Area, Delta state, Nigeria. Abraka is a town in Delta central senatorial district of Delta State with a population estimate of 32,069 and home to the famous Delta State University, Abraka Nigeria. The populace apart from the University Staffs and students are chiefly agrarian. Analysis were done between august to December 2020. Consent was obtained from the community leaders and the heard of each household where rat were obtained with the aid of mouse trap.

\section{Sampling technique}

A total of 100 mouse were obtain from 20 households. Rats were trapped using mouse glue board, measuring $30 \mathrm{~cm}$ in length and 20 $\mathrm{cm}$ in width. After thorough visual inspection of the room to identify rodents' tracks, droppings, the glue board was placed on their path. Pieces of crayfish or smoked fish were placed in the middle of the board as bait. The glue board was left overnight and trapped rodents were collected alive and taken to the laboratory for identification and microbiological analysis. The study was approved by the Delta State University Ethical review Board.

\section{Preparation and Analysis of samples}

Each of the rat samples were picked from the trap using forceps. The skin was swabbed 
using a sterile swab stick. The rats were dissected using a dissecting kit to obtain the large and small intestine. The throat, small and large intestines was also swabbed using a sterile swab stick and transferred respectively into sterile mortar and then crushed using a sterile pestle to homogenize the intestine. The homogenate (Ig) was taken into a sterile test tube for serial dilution, enumeration and plating protocol. ${ }^{12}$ The sample (1g) were collected into a test tube containing $9 \mathrm{mls}$ of distilled water. Serial dilutions was then carried out on 5 test tubes and the 10 and 10 dilution of both dilutions were collected and used for pour plate. The sterile swabs were then streaked plated onto sterilized Nutrient agar, McConkey agar and Saboroud Dextrose agar. Inoculated plates incubated at $37^{\circ} \mathrm{C}$ for 18-24hrs. After incubation in both aerobic and conditions, the colonies were counted using 'Viable Plate count Method' as enumerated by Eby Basiri (Microbiology Biol. 275) ${ }^{13}$.

\section{Biochemical Tests}

The biochemical tests carried out as described in Microbiology laboratory manual (2014) ${ }^{14}$. The tests includes gram stain, motility, citrate utilization test, Oxidase, indole, catalase, triple sugar iron agar (TSI), Bile esculin agar, and sugar fermentation test (lactose, glucose, sucrose, xylose, galactose, maltose, Dsorbitol, D-mannitol mannose). Antibiotic sensitivity tests were performed using the standard diffusion technique(CLSI 2017 ${ }^{15}$. Most commonly used antibiotics discs were used for sensitivity testing and includes Ampicilli, Penicilin, amoxicillin, TrimetoprinSulphamethoxazole, Gentamycin, Ceftriazone, Imipenem and Vancomycin.

\section{Results and Discussion}

We set out to determine the various bacterial and fungi organisms in the gastrointestinal tracts of household mice as well as their antibiotic resistance pattern. The microbial load from different parts of the gut, shows that the small intestines of our sampled rats has more bacterial and fungal load in comparison to the throat and large intestines (Table 1).

Figure.1, shows the various bacteria organisms and relative percentage prevalence obtained from cultures after 24 hours of incubation. It is evident that Bacteroides fragilis and Escherichia coli has the highest percentage prevalence of $28 \%$ and $15 \%$ respectively. This is followed by Salmonella typhimurium (13\%) and Staphylococcus aureus $(9.6 \%)$.

As shown in figure 2, the predominant fungi species isolated includes Candida albican (35.3\%) and other candida species (26.6\%).

Table 2 show the relative number of each bacteria isolates, and their various percentage resistance to each antibiotics used in sensitivity testing. A total of 375 bacteria organisms were isolated. Of this, a total of 327 and 224 bacteria isolates were tested against ampicillin and tetracycline discs respectively. Notably, all 12 species isolated bacteria from culture are nearly $100 \%$ percent resistant to Ampicillin and penicillin(Table 2). More than two-third of the isolates were also resistant to Tetracycline, 224 (77.9\%), AmoxicillinClavulanic acid, 128 (71.5\%), TrimetoprinSulphamethoxazole, $207 \quad(60.2 \%)$ and Ceftriaxone 343 (60.1\%). However, most isolates teste were sensitive to Vancomycin 38 (5.8\%), Clindamycin $96 \quad(21.3 \%)$ and Amikacin 271 (45.5\%).

In recent years, there exist a growing concern about the increase in zoonotic diseases transmission and emergence of resistance organism between house hold rats and human ${ }^{2}$. This indicate risk associated frequent contact between human, household and other human pets. 
The result obtained from this investigation shows an abundant number of bacteria and fungi organisms in the gut of household rats that are possibly transmissible to man. It also shows that over two-third of the bacteria organisms isolated were resistant to commonly used antibiotics such as Ampicillin, Penicillin, Tetracycline, TrimethoprimSuphamethoxazole and Ceftriaxone. The gut microbial population (Table 1) consists of bacteria and fungi which may be symbiotic, neutral or harmful to the host. ${ }^{16}$

These microbiota are important for the host immune response to diseases and maintenance of healthy state ${ }^{16}$. Possible mechanism for abundant microbial load includes genetics, diets and feeding habits. ${ }^{17},{ }^{18}$ The abundant microbes in our results is consistent with report of Li Wen et al., (2017), which shows that gut microbes increases significantly from the stomach, jejunum to large intestines. The large gut harbours up to 1000 different bacterial and additional $1 \times 10^{14}$ different organisms. ${ }^{16}$

The largest gut bacteria flora in this study were bacteriodes fragilis followed by Escerichia coli and Salmonella typhimurium respectively. Similar results have been reported by Geraldine O. Canny et al., (2008) who reported bacteriodes fragilis as the largest gut flora. This result is in contrast to result presented by Tomotari Mitsuoka (1992), who reported that lactobacilli actually predominate in rat and human intestines ${ }^{7,8}$. Possible speculation to differences in gut microbes could be due to the breeding, diets and environmental condition of the host $\mathrm{t}^{19,1,17}$.

Fungi isolates which dominated our study were candida albicans, and other candida species. This shows that fungi are also part of the normal flora of household rats as in human. These results are in agreement with previous studies which shows that candida and other fungi species are part of the rat gut ubiquitous microbiota and also serves as either commensals, pathogens or opportunistic $\operatorname{organisms}^{20,21,22}$.

Perhaps, the most clinically relevant finding in this study is the carriage of antibiotic resistant organisms by these rats (Table 2). As a result of these carriage, transmission of resistant organisms to humans are highly probable through a variety of routes. These routes includes direct contact, the food chain, (where rats are part of the household diets or come into direct contact with food) and contact with direct surfaces. ${ }^{23}{ }^{24}$ This can lead to the advent of difficult-to-manage diseases ${ }^{24,25}$.

Household rats have a closer relationship with humans and they have sought a niche role in human-occupied structures such as houses, classrooms, and restaurants. This, along with other urban rats, are found to host antimicrobial-resistant bacteria such as $E$. coli and $S$. aureus, which can be readily spread to humans by (1) direct or near interaction and (2) ingestion of utensils and fruit. Nonhygienic food handling will escalate this. ${ }^{11}$

Table.1 Microbial load from different parts of rats

\begin{tabular}{|c|c|c|}
\hline Part & Microbial load $\left(\mathbf{c f u} / \mathbf{g X 1 0}^{\mathbf{7}}\right)$ & \\
\hline & Bacteria & Fungi \\
\hline Throat & 2.60 & 1.96 \\
\hline Small intestine & 4.89 & 2.90 \\
\hline Large intestine & 3.73 & 1.20 \\
\hline
\end{tabular}


Table.2 Antimicrobial resistance pattern of bacteria isolates from cultured plates in the study

\section{Antibiotics}

\begin{tabular}{|c|c|c|c|c|c|c|c|c|c|c|c|c|c|}
\hline $\begin{array}{r}\text { No of isolates } \\
\text { Tested }\end{array}$ & 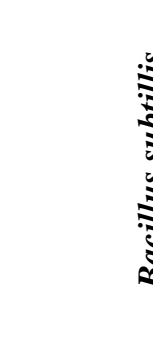 & 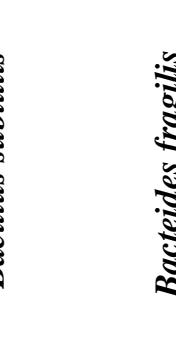 & 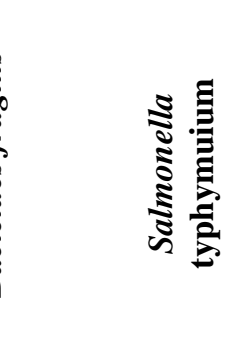 & 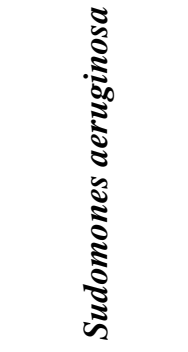 & 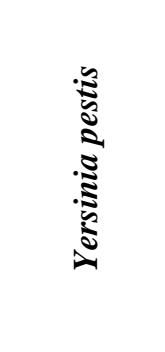 & 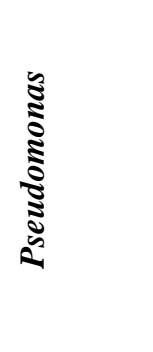 & 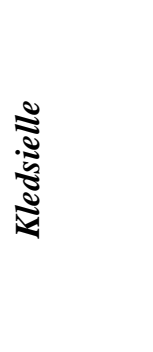 & 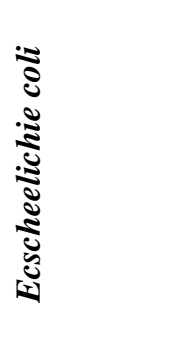 & 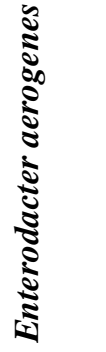 & 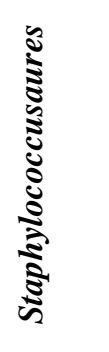 & 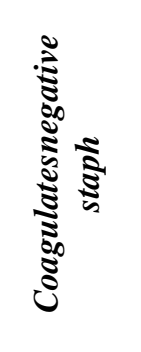 & 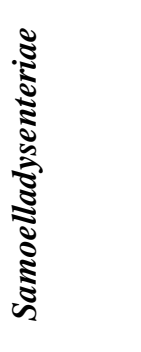 & है \\
\hline \multirow[t]{3}{*}{ Ampicillin } & $15(100)$ & $\begin{array}{l}27 \\
N(\%)\end{array}$ & $\begin{array}{l}17 \\
N(\%)\end{array}$ & $\begin{array}{c}9 \\
\mathbf{N}(\%)\end{array}$ & $\begin{array}{c}7 \\
\mathbf{N}(\%)\end{array}$ & $\begin{array}{c}7 \\
N(\%)\end{array}$ & $\begin{array}{c}13 \\
N(\%)\end{array}$ & $\begin{array}{c}9 \\
\mathbf{N}(\%)\end{array}$ & $\begin{array}{c}2 \\
N(\%)\end{array}$ & $\begin{array}{c}15 \\
\mathbf{N}(\%)\end{array}$ & $\begin{array}{c}8 \\
\mathbf{N}(\%)\end{array}$ & $\begin{array}{c}2 \\
N(\%)\end{array}$ & $\begin{array}{l}375 \\
\mathbf{N}(\%)\end{array}$ \\
\hline & & $103(100)$ & $48(100)$ & $30(100)$ & $0(0)$ & $11(100)$ & $7(100)$ & $55(100)$ & \multicolumn{2}{|c|}{$5(100$} & $35(100)$ & $9(100)$ & $9(100)$ \\
\hline & $15(100)$ & $\mathbf{0}(\mathbf{0})$ & 48(98.0) & $30(80.0)$ & $\mathbf{0}(\mathbf{0})$ & 11(10.8) & $7(20.6)$ & $55(100)$ & \multicolumn{2}{|c|}{$5(100$} & $35(80.0)$ & $9(100)$ & $9(90.0)$ \\
\hline Penicilin & $15(100)$ & $100(80)$ & $48(100)$ & & & 11(100) & 7(98.8) & $55(100)$ & \multicolumn{2}{|c|}{$5(100)$} & $35(80.0)$ & $9(100)$ & $9(100)$ \\
\hline $\begin{array}{c}\text { Sulphamethaxazo } \\
\text { le- } \\
\text { Trimethoprim } \\
\text { Amixillin }\end{array}$ & $\mathbf{0}((\mathbf{0})$ & $\mathbf{0}(\mathbf{0})$ & $48(20.8)$ & $30(45.0)$ & $\mathbf{0}(\mathbf{0})$ & 11(20.6) & $7(70.3)$ & $55(65.5)$ & \multicolumn{2}{|c|}{$5(100)$} & $33(40.6)$ & $9(80.0)$ & $9(100)$ \\
\hline Clavulanic acid & $\mathbf{0}(\mathbf{0})$ & $\mathbf{0}(\mathbf{0})$ & $\mathbf{0}(\mathbf{0})$ & $25(60.5)$ & $\mathbf{0}(\mathbf{0})$ & $\mathbf{0}(\mathbf{0})$ & $\mathbf{0}(\mathbf{0})$ & $50(85.6)$ & \multicolumn{2}{|c|}{$5(80.5)$} & $31(60.5)$ & $9(60.8)$ & $8(80.8)$ \\
\hline Cefoxitin & $15(75.5)$ & $100(70)$ & $\mathbf{0}(\mathbf{0})$ & $29(30.8)$ & $\mathbf{0}(\mathbf{0})$ & $11(45.0)$ & $7(0)$ & $53(70.0)$ & \multicolumn{2}{|c|}{$5(68.0)$} & $35(35.5)$ & $9(40.6)$ & $8(70.6)$ \\
\hline Ceftriaxone & $12(80.1)$ & $102(70)$. & $45(25.0)$ & 27(35.7) & $26(70.7)$ & $11(52,1)$ & $7(0)$ & $55(86.0)$ & \multicolumn{2}{|c|}{$5(100)$} & $35(80.8)$ & $9(80.5)$ & $9(40.9$ \\
\hline Chloramphenicol & $15(30.4)$ & $98(5.0)$ & $48(15.0)$ & $25(75.8)$ & $\mathbf{0}(\mathbf{0})$ & $\mathbf{0}(\mathbf{0})$ & 7(1.7) & $50(68.9)$ & \multicolumn{2}{|c|}{$5(89.6)$} & $30(60.6)$ & $9(40.0)$ & $7(30.9)$ \\
\hline Erythromycin & $\mathbf{0}(\mathbf{0 . 0})$ & $\mathbf{0}(\mathbf{0})$ & $\mathbf{0}(\mathbf{0})$ & $\mathbf{0}(\mathbf{0})$ & $\mathbf{0}(\mathbf{0})$ & $11(60.0)$ & $5(60.8)$ & $\mathbf{0}(\mathbf{0})$ & \multicolumn{2}{|c|}{$5(70.4)$} & $30(30.5)$ & $8(100)$ & $7(80.5)$ \\
\hline Ciprofloxacin & $\mathbf{0}(\mathbf{0})$ & $\mathbf{0}(\mathbf{0})$ & $48(15.0)$ & $25(5.6)$ & $26(70.0)$ & 11(3.0) & $7(0)$ & $55(42.9)$ & \multicolumn{2}{|c|}{$5(65.5)$} & $35(50.9)$ & $9(50.0$ & $7(30.7)$ \\
\hline Imipenem & $\mathbf{0}(\mathbf{0})$ & $\mathbf{0}(\mathbf{0})$ & $48(15.0)$ & $25(0)$ & $26(0)$ & $11(0)$ & $7(0)$ & $35(20.5)$ & \multicolumn{2}{|c|}{$5(70.0)$} & $30(80.8)$ & $6(80.5)$ & $6(0)$ \\
\hline Nalidixic Acid & $\mathbf{0}(\mathbf{0})$ & $\mathbf{0}(\mathbf{0})$ & $\mathbf{0}(\mathbf{0})$ & $\mathbf{0}(\mathbf{0})$ & $\mathbf{0}(\mathbf{0})$ & $9(20.8)$ & $\mathbf{0}(\mathbf{0})$ & $30(70.4)$ & \multicolumn{2}{|c|}{$\mathbf{0}(\mathbf{0})$} & $\mathbf{0}(\mathbf{0})$ & $\mathbf{0}(\mathbf{0})$ & $\mathbf{0}(\mathbf{0})$ \\
\hline Gentamicin & $15(80.0)$ & $\begin{array}{c}103 \\
(25.9)\end{array}$ & $40(70.0)$ & $25(24.9)$ & $25(45.9)$ & $11(40.2)$ & $7(57.5)$ & $53(60.0$ & \multicolumn{2}{|c|}{$\mathbf{0}(\mathbf{0})$} & $30(60.5)$ & $6(0)$ & $7(70.8)$ \\
\hline Vancomycin & $2(8.5)$ & $\mathbf{0}(\mathbf{0})$ & $\boldsymbol{0}(\mathbf{0})$ & $\mathbf{0}(\mathbf{0})$ & $\mathbf{0}(\mathbf{0})$ & $\mathbf{0}(\mathbf{0})$ & $\mathbf{0}(\mathbf{0})$ & $\mathbf{0}(\mathbf{0})$ & \multicolumn{2}{|c|}{$\mathbf{0}(\mathbf{0})$} & $30(3.0)$ & $6(0)$ & $\mathbf{0}(\mathbf{0})$ \\
\hline Nitrofurantoin & $\mathbf{0}(\mathbf{0})$ & $\mathbf{0}(\mathbf{0})$ & $\mathbf{0}(\mathbf{0})$ & $\mathbf{0}(\mathbf{0})$ & $\mathbf{0}(0)$ & $0(0)$ & $5(70.1)$ & $\mathbf{0}(\mathbf{0})$ & \multicolumn{2}{|c|}{$\mathbf{0}(\mathbf{0})$} & $\mathbf{0}(\mathbf{0})$ & $\mathbf{0}(\mathbf{0})$ & $\mathbf{0}(\mathbf{0})$ \\
\hline Metronidazole & $15(2.0)$ & $103(0)$ & $\mathbf{0}(\mathbf{0})$ & $\mathbf{0}(\mathbf{0})$ & (0) & $\mathbf{0}(\mathbf{0})$ & $\mathbf{0}(\mathbf{0})$ & $\mathbf{0}(\mathbf{0})$ & \multicolumn{2}{|c|}{$\mathbf{0}(\mathbf{0})$} & $\mathbf{0}(\mathbf{0})$ & $\mathbf{0}(\mathbf{0})$ & $\mathbf{0}(\mathbf{0})$ \\
\hline Amikacin & $15(5.0)$ & $\begin{array}{c}100 \\
(67.0)\end{array}$ & $40(45.5)$ & $25(6.0)$ & $26(65.6)$ & $\mathbf{0}(\mathbf{0})$ & $\mathbf{0}(0)$ & $\mathbf{0}(\mathbf{0})$ & \multicolumn{2}{|c|}{ 35(89.5) } & $30(40,4)$ & $\mathbf{0}(\mathbf{0})$ & $0(0)$ \\
\hline Clindamycin & $\mathbf{0}(\mathbf{0})$ & $\mathbf{0}(\mathbf{0})$ & $\mathbf{0}(\mathbf{0})$ & $25(30.3)$ & $\mathbf{0}(\mathbf{0})$ & $\mathbf{0}(\mathbf{0})$ & $\mathbf{0}(\mathbf{0})$ & $\mathbf{0}(\mathbf{0})$ & \multicolumn{2}{|c|}{$30(55.0)$} & $35(30.5)$ & $6(0)$ & $\mathbf{0}(\mathbf{0})$ \\
\hline
\end{tabular}


Fig.1 Various bacteria species isolated from the gastrointestinal tracts of household rats in Abraka community

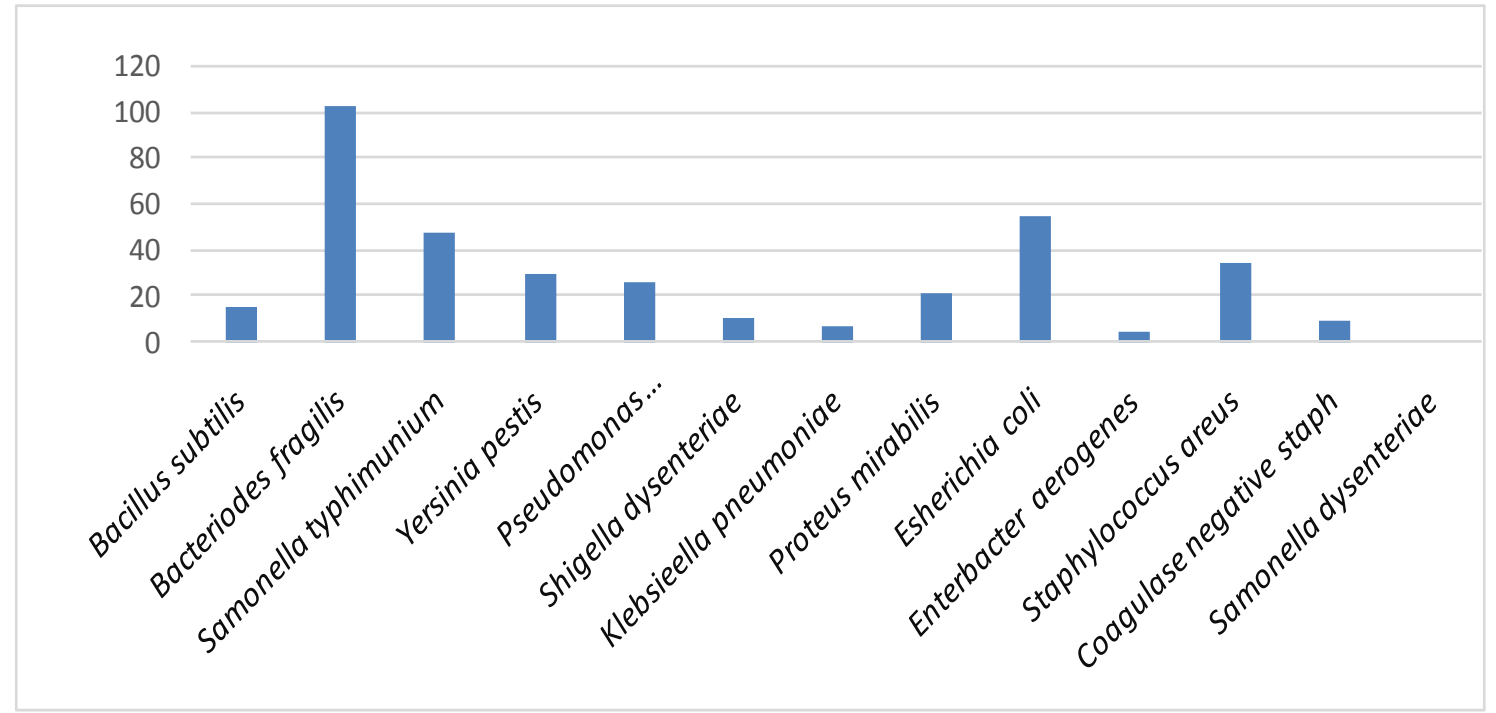

Fig.2 Various types of fungi isolates from the gastrointestinal tracts of household rats in Abraka community

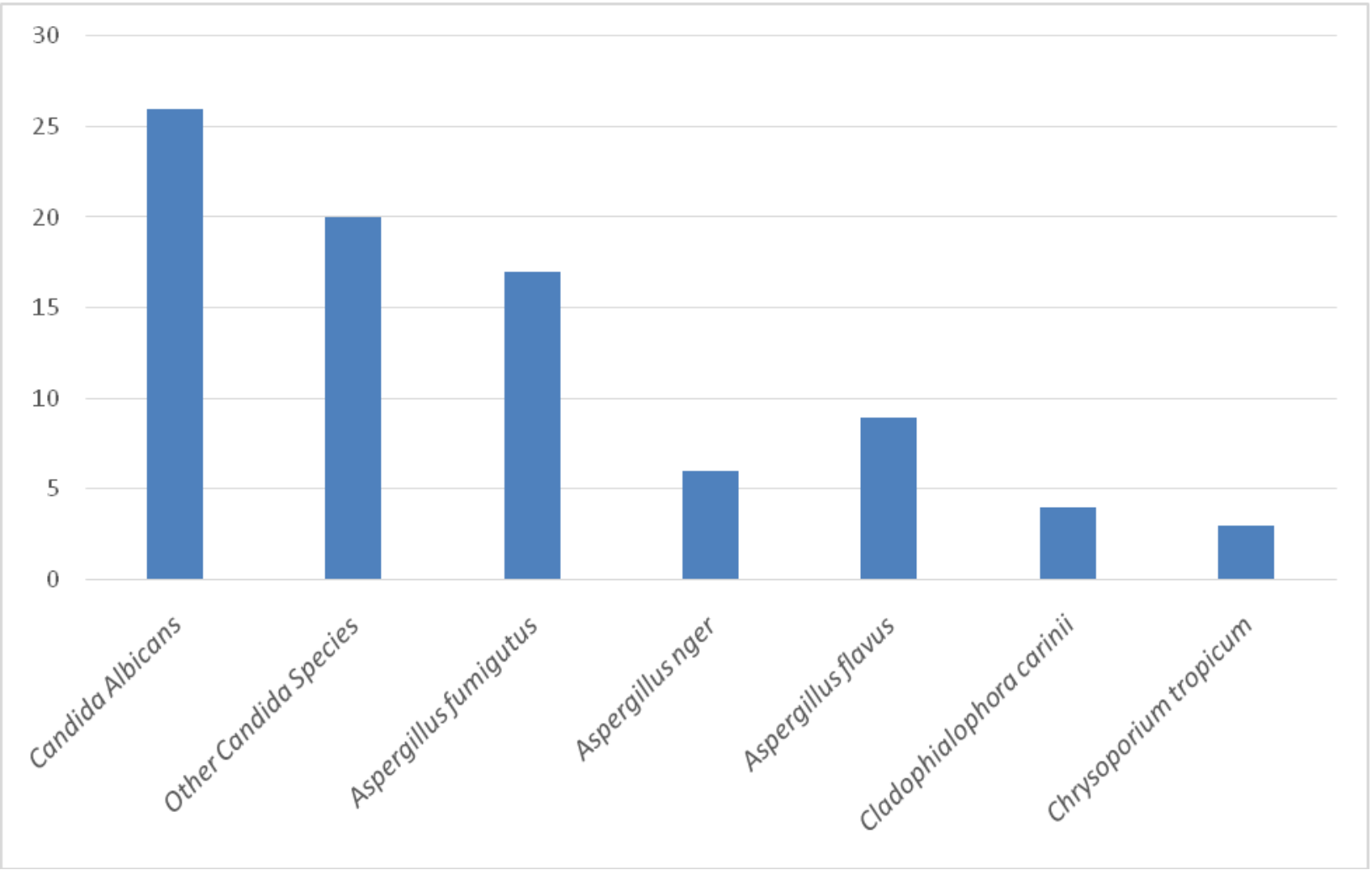


Possible mechanisms for antibiotic resistance includes; (1) the presence of antimicrobial resistance genes (intrinsic resistance), (2) the selective pressure exerted by excessive antibiotic use by humans ${ }^{28,29}$.

Our study implies that over $66 \%$ of bacteria isolates were resistant to commonly used antibiotic. This results is consistence with reports by Alermale Admas et al., (2020), Melkanu Abebe Abebe et al., (2019), Richard J. Fair and Yithak Tor (2014). ${ }^{30}, 31,32$ In contrast to our study, a lower percentage of $44.4 \%$ of total isolated organisms being resistant to commonly used antibiotics has been reported. ${ }^{33}$ Speculated reasons for differences in antibiotic resistance pattern could due to techniques, equipment used for antibiotics resistant testing, rational use of antibiotics, and local resistant pattern. ${ }^{34}$

Of the 38 isolates that were tested against Vancomycin, an average of $3.8 \%$ were resistant. Rodriques, et al., (2002) reported a lower average vancomycin resistance of $0.0 \%$ while higher percentages of 15 to $30 \%$ have been reported by other several other studies. 34,31,35,36,37

There are little or scanty studies on the burden of organisms in the gut of house rats and its impact on house hold dwellers in our environment ${ }^{38}$. This study therefore serve as baseline study and may be useful for Health Practitioners, environmental impact assessment officers and policy makers. Household rats have long been a concern in rural areas, eating and contaminating stored food, spreading disease, and degrading the physical environment ${ }^{39,11,27 .}$

The underreporting of rats zoonoses and, in many cases, inadequate attention paid to the diagnosis and management of these essential diseases are two main messages to emerge from this study $\mathrm{y}^{3,5}$.
When exploring ways to minimize the impact of rodents on rural livelihoods, there are two key issues to consider: 1) recognizing the current impact of rodents on food protection, health, and nutrition of communities, as well as existing awareness, behaviour, and practices of people regarding their rodent problems, and 2) designing cost-effective strategies that can be sustained. ${ }^{38}$

The results of this study should be interpreted with caution as it was done in a small community in Abraka, Delta State, Nigeria.

This therefore limits its generalization. Our techniques of disk diffusion as methods of resistance testing could also be prone to technical and observer's error.

Antifungi resistance testing testing were not included in our study due paucity of equipment. More extensive studies on burden of household rat borne pathogens using modern techniques are required in our environment.

Taken together, the result of this study indicate a high burden of bacteria, fungi and bacteria resistance organisms in household rats that can be transmitted to man.

It also suggest that increased reporting of this zoonotic disease coupled with proper diagnosis and management are ways of mitigating this burden.

\section{Acknowledgments}

We are grateful to the members of the Department of Microbiology, Faculty of Science, Delta State University, Abraka. We also thank members of Abraka community for giving us consent to collect rats from their various households. 


\section{References}

Jahan N A, Lindsey L L, Larsen P A. The Role of Peridomestic Rodents as Reservoirs for Zoonotic Foodborne Pathogens. doi:10.1089/vbz.2020.2640

Gwenzi W, Chaukura N, Muisa-Zikali N, et al., Insects, rodents, and pets as reservoirs, vectors, and sentinels of antimicrobial resistance. Antibiotics. 2021;10(1):1-42. doi:10.3390/antibiotics10010068

Meerburg B G, Singleton G R, Kijlstra A. Rodent-borne diseases and their risks for public health Rodent-borne diseases and their risks for public health. Crit Rev Microbiol. 2009;35(3):221-270. doi:10.1080/10408410902989837

Fornefett J, Busch A, Döpping S, Hotzel H, Rimek D. Bacterial gastroenteritis caused by the putative zoonotic pathogen Campylobacter lanienae: First reported case in Germany. Access Microbiol. 2021;3(3). doi:10.1099/acmi.0.000199

Meerburg B G, Kijlstra A. Role of rodents in transmission of Salmonella and Campylobacter. J Sci Food Agric. 2007;87(15):2774-2781. doi:10.1002/jsfa.3004

Inoue $\mathrm{R}$, Ushida $\mathrm{K}$. Development of the intestinal microbiota in rats and its possible interactions with the evolution of the luminal IgA in the intestine. FEMS Microbiol Ecol. 2003;45(2):147-153. doi:10.1016/S0168-6496(03)00134-X

Canny G O, McCormick B A. Bacteria in the intestine, helpful residents or enemies from within? Infect Immun. 2008;76(8):3360-3373. doi:10.1128/IAI.00187-08

Mitsuoka T. The Human Gastrointestinal Tract. In: The Lactic Acid Bacteria Volume 1. Springer US; 1992:69-114. doi:10.1007/978-1-4615-3522-5_4

Hallen-Adams H E, Suhr M J. Fungi in the healthy human gastrointestinal tract. Virulence. 2017;8(3):352. doi:10.1080/21505594.2016.1247140

Hof H. Pilze im Darm - das Mykobiom des Darms. Z Gastroenterol. 2017;55(8):772-778. doi:10.1055/s0043-112657

Gwenzi W, Chaukura N, Muisa-Zikali N, et al., Insects, rodents, and pets as reservoirs, vectors, and sentinels of antimicrobial resistance. Antibiotics. 2021;10(1):1-42. doi:10.3390/antibiotics 10010068

Serial Dilutions and Plating: Microbial Enumeration | Protocol.

Bassiri E. Microbiology BIOL 275. (PDF) Microbiology Laboratory Manual.

Fujimura K E, Slusher N A, Cabana M D, Lynch S V. Role of the gut microbiota in defining human health. Expert Rev Anti Infect Ther. 2010;8(4):435-454. doi:10.1586/eri.10.14

Wen L, Duffy A. Factors influencing the gut microbiota, inflammation, and type 2 diabetes. J Nutr. 2017;147(7):1468S1475S. doi:10.3945/jn.116.240754

Stringer A M, Gibson R J, Logan R M, et al., Gastrointestinal microflora and mucins may play a critical role in the development of 5-fluorouracil-induced gastrointestinal mucositis. Exp Biol Med. 2009;234(4):430-441. doi:10.3181/0810-RM-301

Tomas J, Langella P, Cherbuy C. The intestinal microbiota in the rat model: major break throughs from new technologies. Anim Health Res Rev. 2012;13(1):54-63. doi:10.1017/S1466252312000072

Fidel P L. Candida albicans: from commensal to pathogen. In: Medical Importance of the Normal Microflora. Springer US; 1999:441-476. doi:10.1007/978-14757-3021-0_18. 
Böhm L, Torsin S, Tint S H, Eckstein M T, Ludwig T, Pérez J C. The yeast form of the fungus Candida albicans promotes persistence in the gut of gnotobiotic mice. PLoS Pathog. 2017;13(10).

doi:10.1371/journal.ppat.1006699

Basmaciyan L, Bon F, Paradis T, Lapaquette P, Dalle F. "Candida Albicans Interactions With The Host: Crossing The Intestinal Epithelial Barrier." Tissue Barriers. 2019;7(2). doi:10.1080/21688370.2019.1612661

Huff R, Pereira R I, Pissetti C, et al., Antimicrobial resistance and genetic relationships of enterococci from siblings and non-siblings Heliconius erato phyllis caterpillars. PeerJ. 2020;2020(2). doi:10.7717/peerj.8647

Pietri J E. Case not closed: Arguments for new studies of the interactions between bed bugs and human pathogens. Am J Trop Med Hyg. 2020;103(2):619-624. doi:10.4269/ajtmh.20-0121

Kruse H, Sørum H. Transfer of multiple drug resistance plasmids between bacteria of diverse origins in natural microenvironments. Appl Environ Microbiol. 1994;60(11).

Kolawole O M, Anjorin E O, Adekanle D A, Kolawole C F, Durowade K A. Seroprevalence of rubella $\mathrm{IgG}$ antibody in pregnant women in osogbo, Nigeria. Int J Prev Med. 2014;5(3):287-292. Accessed December 5, 2020. /pmc/articles/PMC4018637/?report=ab stract

Zhong X S, Li Y Z, Ge J, et al., Comparisons of microbiological characteristics and antibiotic resistance of Klebsiella pneumoniae isolates from urban rodents, shrews, and healthy people. BMC Microbiol. 2020;20(1). doi:10.1186/s12866-020-1702-5

C Reygaert W. An overview of the antimicrobial resistance mechanisms of bacteria. AIMS Microbiol. 2018;4(3):482-501. doi:10.3934/microbiol.2018.3.482

Davies J, Davies D. Origins and Evolution of Antibiotic Resistance. Microbiol Mol Biol Rev. 2010;74(3):1092-2172. doi:10.1128/MMBR.00016-10

Admas A, Gelaw B, Belaytessema, Worku A, Melese A. Proportion of bacterial isolates, their antimicrobial susceptibility profile and factors associated with puerperal sepsis among post-partum/aborted women at a referral Hospital in Bahir Dar, Northwest Ethiopia. Antimicrob Resist Infect Control. 2020;9(1). doi:10.1186/s13756-019-0676-2

Abebe M, Tadesse S, Meseret G, Derbie A. Type of bacterial isolates and antimicrobial resistance profile from different clinical samples at a Referral Hospital, Northwest Ethiopia: Five years data analysis. BMC Res Notes. 2019;12(1). doi:10.1186/s13104-0194604-6

Fair R J, Tor Y. Antibiotics and bacterial resistance in the 21 st century. Perspect Medicin Chem. 2014;6(6):25-64. doi:10.4137/PMC.S14459

Nigussie D, Makonnen E, Legesse B A, Fekadu A, Davey G. Antimicrobial susceptibility of bacteria isolated from the infected wounds of patients with lymphoedema in East Wollega, Ethiopia. Trans $R$ Soc Trop Med Hyg. 2020;114(12):962-973. doi:10.1093/trstmh/traa143

Plaza-Rodríguez C, Alt K, Grobbel M, et al., Wildlife as Sentinels of Antimicrobial Resistance in Germany? Front Vet Sci. 2021;7. doi:10.3389/fvets.2020.627821

Vera-Lise Tulstrup M, Gerd Christensen E, Carvalho V, et al., Antibiotic Treatment Affects Intestinal 
Permeability and Gut Microbial Composition in Wistar Rats Dependent on Antibiotic Class. Published online 2015.

doi:10.1371/journal.pone.0144854

Faron M L, Ledeboer N A, Buchan B W. Resistance mechanisms, epidemiology, and approaches to screening for vancomycin-resistant Enterococcus in the health care setting. $J$ Clin Microbiol. 2016;54(10):2436-2447. doi:10.1128/JCM.00211-16

Fridkin S K, Edwards J R, Courval J M, et al., The effect of vancomycin and thirdgeneration cephalosporins on prevalence of vancomycin-resistant enterococci in 126 U.S. adult intensive care units. Ann Intern Med.
2001;135(3):175-183.

doi:10.7326/0003-4819-135-3200108070-00009

Belmain S R, Meyer A, Partnership A, et al., Assessment of the Impact of Rodents on Rural Household Food Security and the Development of EcologicallyBased Rodent Management Strategies in Zambézia Province, Mozambique Developing Rodent Management Strategies for Rural Households in Mozambique.; 1999.

Özkara A, Akyil D, Konuk M. Pesticides, Environmental Pollution, and Health. In: Environmental Health Risk Hazardous Factors to Living Species. InTech; 2016. doi:10.5772/63094.

\section{How to cite this article:}

Egbagba, J. E., U. B. Owhe-Ureghe, M. A. Alex-Wele, S.D. Lawson and Orutugu, L.A. 2021. Microbial Load and Resistance Pattern of Bacteria Organisms in the Gastrointestinal Tract of Household Rat. Int.J.Curr.Microbiol.App.Sci. 10(08): 765-774. doi: https://doi.org/10.20546/ijcmas.2021.1008.086 